\title{
The State Of Higher Education In 2012
}

Frank L. Kurre, National Managing Partner, Not-for-Profit and Higher Ed. Practices, Grant Thornton LLP, USA

Larry Ladd, Director, Higher Ed. Practice, Grant Thornton LLP, USA

Mary F. Foster, Managing Director, Higher Ed. Practice, Grant Thornton LLP, USA

Michael J. Monahan, National Practice Leader, Not-for-Profit and Higher Ed. Compensation

and Benefits, Grant Thornton LLP, USA

Daniel Romano, Partner-in-Charge, Not-for-Profit Tax Practice, Grant Thornton LLP, USA

\section{INTRODUCTION}

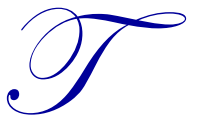

his first edition of the State of Higher Education is dedicated to Dennis Murray, the President of Marist College (Poughkeepsie, New York). Dennis was my inspiration in developing this first of what I expect will be an annual publication. Over the past 33 years Dennis has served as president of Marist. Through his leadership and vision, Marist College has grown from a local institution to one with an international reputation for excellence. The Princeton Review named Marist one of the best 371 colleges in the country, and their School of Management one of the top 290 business schools in the world. Forbes and The Princeton Review call Marist one of the "25 most connected campuses" in America. U.S. News \& World Report consistently places Marist in its top tier. Kiplinger's Personal Finance Magazine and Barron's called Marist College one of the nation's best buys in college education. Yahoo! Internet Life magazine selected Marist for its list of the 100 most wired campuses in the nation. The John Templeton Foundation placed the College on its elite honor roll of only 100 academic institutions noted for teaching character development. Careers and Colleges magazine picked Marist as one of 14 "schools that rule," providing "strong academic programs, terrific professors, a vibrant student life, (and) other opportunities for personal development." My wife and I are proud Marist parents and have seen firsthand that these accolades are well deserved for the College and President Murray.

The higher education sector is experiencing an escalating pace of change. Even colleges and universities with the greatest resources and strongest brands are confronting change, particularly as a result of the digital revolution that is radically impacting modes of learning and accessibility to knowledge. These changes are driven by market pressures - i.e., by the demands and expectations of students and faculty. At the same time, all of higher education continues its evolution in response to ongoing price pressures, to reduced governmental support, to growing competition from the for-profit higher education sector, to its own ethical challenges, and to changes in the regulatory environment. Boards, presidents, provosts and CFOs are addressing these risks and challenges with new strategies and unique action plans that are a far cry from traditional approaches to higher education.

The state of higher education in 2012 is the first in Grant Thornton LLP's annual series of white papers for colleges and universities. Our goal is to offer advice and guidance for trustees and management of higher education institutions as they respond to transformational change through strategic planning and enterprise risk management. We highlight key issues and external forces that are impacting the higher education community, and share trends and best practices. We hope you find this paper helpful as a planning tool. Comments to frank.kurre@us.gt.com are always appreciated.

Frank L. Kurre

National Managing Partner

Not-for-Profit and Higher Education Practices

\section{EDUCATION IS BECOMING “ANYTIME AND ANYWHERE”}

\author{
Larry Ladd, Director, Higher Education Practice, Grant Thornton LLP
}

This past year demonstrated once again that higher education is becoming dissociated from geographical limitations. Those who think to themselves "MIT is in Cambridge" don't see the full picture: In addition to providing classes at its physical location, MIT now offers online access to courses, along with certificates 
documenting completion of those courses. The university will soon "host a virtual community of millions of learners around the world." ${ }^{\prime 1}$ But leaping over boundaries isn't limited to Web-based outreach. For example, Boston-based Northeastern University, like many other institutions of higher learning, has established a branch campus far from its nominal location. Northeastern is opening one campus in Charlotte, N.C., and plans to open more in Seattle, Wash., and elsewhere. Sebastian Thrun, formerly a tenured professor of computer science at Stanford, has quit his job to establish Udacity, which will offer low-cost online classes. ${ }^{2}$ Southern New Hampshire University, which is a small college if you look at its campus, has more than 7,000 online students and is expanding rapidly. It has already become "the second-largest online education provider in college-saturated New England," according to The Chronicle of Higher Education. ${ }^{3}$

In going where the students are rather than expecting the students to come to them, these institutions are following the examples already set by for-profit entities such as the University of Phoenix and the Education Management Corporation. While many think only of the online component of for-profits such as these, they also have significant land-based presences. And because these for-profit institutions locate their classes where their students are, they move from locale to locale as the market changes. For that reason, they lease space rather than constructing buildings, freeing capital to be used for other purposes. ${ }^{4}$

Intermediary entities are emerging to facilitate the sharing of knowledge and courses between faculty and students, sometimes through a formal institution and sometimes not. In one example, The Faculty Project, established by start-up Udemy, allows faculty at elite colleges and universities to provide their courses for free over an online platform. ${ }^{5}$ Through online learning, students attending even the smallest universities will have access to some of the best courses and faculty in the world. And even at the K-12 level, online and distance learning are establishing a beachhead. ${ }^{6}$

Accreditors are scrambling, trying to figure out how to protect quality in the new online world. ${ }^{7}$ And the U.S. News \& World Report is scrambling for ways to fit online programs into its ranking system. ${ }^{8}$

Colleges and universities that stay landlocked and bound to only face-to-face classroom learning will quickly find that they are out of step with the expectations of their students and faculty — and that they are losing both students and faculty to the new world that is emerging.

\section{For more information}

Some good summaries of current trends in online education are as follows:

- Carey, Kevin. "What Colleges Should Learn From Newspapers' Decline," The Chronicle of Higher Education, April 3, 2009.

- $\quad$ Keller, Bill. "The University of Wherever," The New York Times, Oct. 2, 2011.

- $\quad$ Teachout, Zephyr. “A Virtual Revolution is Brewing for Colleges,” The Washington Post, Sept. 13, 2009.

- Wise, Daniel. “An 'Arab Spring' of Free Online Higher Education,” The Washington Post, Feb. 3, 2012.

\footnotetext{
${ }^{1}$ Parry, Marc. "MIT Will Offer Certificates to Outside Students Who Take Its Online Courses," The Chronicle of Higher Education, Dec. 19, 2011.

${ }^{2}$ DeSantis, Nick. "Stanford Professor Gives up Teaching Position, Hopes to Reach 500,000 Students at Online Start-Up," The Chronicle of Higher Education, Jan. 23, 2012.

Available at chronicle.com/blogs/wiredcampus/stanford-professor-gives-up-teaching-position-hopes-to-reach-500000-studentsat-online-start-up/35135

${ }^{3}$ Parry, Marc. “Online Venture Energizes Vulnerable College," The Chronicle of Higher Education, Aug. $28,2011$.

${ }^{4}$ Lewin, Tamar. "Joining Trend, College Grows Beyond Name," The New York Times, Dec. 27, 2011.

${ }^{5}$ Kolowich, Steve. "Free Courses, Elite Colleges," Inside Higher Ed, Jan. 27, 2012.

${ }^{6}$ Layton, Lyndsey, and Brown, Emma. "Virtual Schools Are Multiplying, But Some Question Their Educational Value," The Washington Post, Nov. 26, 2011.

${ }^{7}$ Kelderman, Eric. "Online Programs Face New Demands From Accreditors," The Chronicle of Higher Education, Nov. 6, 2011.

${ }^{8}$ DeSantis, Nick. "U.S. News Sizes up Online-Degree Programs, Without Specifying Which Is No. 1," The Chronicle of Higher Education, Jan. 10, 2012.
} 


\title{
TECHNOLOGY WILL CONTINUE TO TRANSFORM YOUR INSTITUTION
}

\author{
Larry Ladd, Director, Higher Education Practice, Grant Thornton LLP
}

The technology revolution is occurring within colleges and universities more than in any other industry, led by students and faculty always looking for better ways to learn, to teach and to conduct research. Administrations are following their lead. Colleges and universities are integrating IT into their educational offerings, back-office administration and marketing methods. According to Inside Higher Ed's Lev Gonick, "This past year's experimentation by Stanford's much-publicized global offering to tens of thousands of learners around the world followed by MIT's MITx initiative" demonstrated the seismic shift in how even our most storied institutions are embracing technological innovation to do more with less.

The increased pace of this innovation is in part a response to economic pressures. Tuition costs and student debt levels are climbing higher each year, while public investment in higher education is being scaled back. It may be only a matter of time before the aggregate weight of an old-school cost structure becomes unsustainable.

Technological innovation is laying the foundation for broad curricula, numerous delivery methods and unlimited network access to knowledge sources unbound by geographical limitations.

Change is called for, and technology could prove to be part of the solution by bringing down the cost of administering, marketing and delivering education to a broad spectrum of learners. Technological innovation is laying the foundation for broad curricula, numerous delivery methods and unlimited network access to knowledge sources unbound by geographical limitations. This same innovation represents the way to keep our higher education institutions relevant in today's global community.

With the adoption of each new application or system solution, higher education's dependence on IT grows as a way to reach distance learners, reduce costs and enhance the overall learning experience. As educators seek long-term solutions to today's pressing problems, technology has the potential to be many things to many institutions.

As changes to IT are rolled out, even more possibilities for teaching and connecting with students — and keeping them safe - emerge. Technology is a laboratory for change in higher education. Whether an institution leads or follows the technological charge, the competitive, economic and social pressure to embrace digital innovation grows each year.

\section{Online education}

Online education, also known as distance education, uses the Internet to provide an interactive, dynamic learning space that may integrate conference call technology with browser-enabled applications. Students can interact with teachers and other students via the Web, watch video lectures of premier instructors, and gain access to digitized texts. Advocates of distance learning contend that online professors are able to spend less time preparing materials and more time teaching students how to interpret and use information.

Whether spurned as a low-quality learning alternative or praised for its potential to reach more learners, the prospect of online education tends to elicit strong emotions and widely differing viewpoints. The argument about whether Web-based tools do indeed facilitate high-quality education in a secure environment has by no means been settled. "By taking advantage of technology, we can deliver more individualized learning and in so doing improve learning and reduce costs," says Robert W. Mendenhall in The Chronicle of Higher Education. ${ }^{10}$

\footnotetext{
${ }^{9}$ Gonick, Lev. "The Year Ahead in IT, 2012," Inside Higher Ed, Jan. 3, 2012. Available at www.insidehighered.com/views/2011/01/03/gonick

${ }^{10}$ Mendenhall, Robert W. "How Technology Can Improve Online Learning — and Learning in General," The Chronicle of Higher Education, Nov. 6, 2011.
} 
The debate over quality, though, may be losing some of its heat, given the release of recent studies that affirm the high caliber of online offerings. A 2010 meta-analysis and review of distance education studies published by the U.S. Department of Education concluded that "online learning was as good as or slightly more effective than traditional face-to-face instruction." ${ }^{11}$ And officials at institutions of higher learning are somewhat confident about the prospects for distance education: About 50 percent of college presidents responding to a recent Pew Research Center survey expect that in 10 years' time, the majority of students will take at least one college course online, compared with 15 percent of students today. ${ }^{12}$

As online learning evolves, distance education is expanding the delivery options and learning strategies available to institutions and students. In Chicago, one school has abandoned instructor-led, classroom-based courses altogether, instead relying on screen time to deliver accredited materials and real-time teaching at a lower cost. The New York Times reports that lower cost and greater accessibility prompted the AFL-CIO to partner with the National Labor College and The Princeton Review to create a new accredited degree-granting online institution devoted to educating the federation's 11.5 million members and their families. ${ }^{13}$ "With classes priced competitively to community colleges, the option is cheaper than most four-year colleges and for-profit schools," Steven Greenhouse writes. ${ }^{14}$

The use of hybrid learning environments that blend classroom and online instruction is growing, as well. Under this model, students may come to campus for an intensive period of face-to-face instruction over a span of days, evenings or weekends, after which distance learning addresses the remainder of the coursework. This format usually reduces facility costs and minimizes disruption to students balancing the demands of school and work.

As online learning channels broaden in scope, quality and accessibility, leaders in higher education face challenges on a variety of fronts:

Loss of location advantage. Location becomes increasingly less relevant to students and faculty when learning is delivered online. Having only a single land-based campus will become a strategic and recruiting challenge. In the United States alone, there are more than 3,500 colleges and universities, all of which - until recently - have been held captive by their location. The location of a campus and the attributes of a college town become less important when courses are available anywhere, anytime.

Strong brands' power grows. The proliferation of low-cost distance education alternatives threatens to undermine school branding. For the first time, students are gaining Web-based access to courses at some of the most prestigious schools in the United States, including MIT and Harvard. By offering free or discounted online courses that grant certification to students who are not otherwise enrolled there, institutions such as these extend their powerful brands into the market space of other colleges and universities.

On the other hand, these trends present opportunities for colleges and universities to expand well beyond their campus footprint into a global community of learners. In its current iteration, online education is an equalopportunity phenomenon: All colleges and universities have a similar opportunity to take in learners far outside the geographical area from which they have traditionally drawn their student body. Smaller schools can act big by using technology to benefit from inbound marketing. For example, a student in Kenya who is interested in architecture is able to find and apply for instructor-led online courses at the Boston Architectural College.

\section{Digital information}

The advent of the digital age has altered the way we receive and disseminate information. Whether it is health records, student records or Google Docs, digital information is rapidly leveling the knowledge playing field among colleges and universities.

\footnotetext{
${ }^{11}$ Ibid.

${ }^{12}$ Young, Jeffrey R. "College Presidents Are Bullish on Online Education But Face a Skeptical Public," The Chronicle of Higher Education, Aug. 28, 2011.

${ }^{13}$ Greenhouse, Steven. “A.F.L.-C.I.O. Creates Online College for Union Families,” The New York Times, Jan. 15, 2010.

14 Ibid.
} 
The days when a world-class library was a selling point for students and alumni are disappearing. Harvard's once-sizable competitive advantage from its libraries is being whittled away as its collections are digitized and made accessible to students, faculty and the global community. Sixty-two percent of college presidents responding to the Pew Research Center study say that more than half of students' textbooks will be digital in 10 years. ${ }^{15}$ The extent to which an institution's collections have been digitized — and are therefore accessible online and the breadth of the institution's shared network matter far more than the texts sitting in the stacks.

\section{Social media}

Social media applications are also transforming the look and feel of higher education. Facebook, LinkedIn and Twitter are creating communities of learners where education and contemporary culture intersect. Students, alumni and faculty long used to Blackboard and other course management software for facilitating the give-and-take of information suddenly have new forums for small-group meetings and discussions, and additional channels for delivering learning materials.

Social media delivery models lower barriers to communication. Students too shy to speak out in class are more apt to offer up their viewpoints via Facebook, tweet a link to a topical article, or join one of LinkedIn's many professional discussion groups to test real-world applications of classroom learning. The challenge for higher education is determining how to harness that opportunity to create communities, distribute materials, and provide leading-edge exchange platforms that matter to today's learners and prospective students.

\section{Mobile devices}

Students are prepared to use smartphones and tablets to navigate institutional resources and use campus services. ${ }^{16}$ Colleges and universities are responding with mobile applications that put education on devices students prefer.

More technology providers than ever before offer mobile applications. Institutions of higher learning have made significant gains in deploying mobile apps over the past year alone. The Campus Computing Survey asked colleges and universities whether they were using mobile apps or planning to do so during the next academic year. The survey found that the number of public four-year colleges that expected to go mobile or had already done so had grown substantially, from 17.8 percent in fall 2010 to 43.6 percent in fall 2011. Of public universities surveyed, 55.3 percent deploy or plan to deploy mobile apps, versus 32.5 percent last year. The number of private institutions saying they offer or will soon offer mobile apps increased from 42.2 percent in 2010 to 50 percent in 2011, while the number of community colleges using mobile apps or planning to do so rose from 12.4 percent in 2010 to 40.9 percent in $2011 .^{17}$

This data bears out our belief that the affordable cost of going mobile will lead more colleges and universities to adopt applications that deliver instant messaging and on-the-go learning support.

\section{Cloud computing}

Cloud computing has not seen nearly the bump in use that mobile applications have. It is, however, expected to evolve rapidly over the next five to 10 years. ${ }^{18}$ Providers of cloud computing are already making inroads into the academic market, replacing servers and data storage at institutions of higher learning. Cloud computing puts shared resources, software and information on the Internet to be managed by commercial providers. Practically speaking, cloud computing allows colleges and universities to select enterprise activities to move off campus for

\footnotetext{
${ }^{15}$ Young, Jeffrey R. "College Presidents Are Bullish on Online Education But Face a Skeptical Public," The Chronicle of Higher Education, Aug. 28, 2011.

16 The Campus Computing Project. The 2011 Campus Computing Survey, October 2011. Available at www.campuscomputing.net/survey

${ }^{17}$ Ibid.

18 Ibid.

(C) 2012 The Clute Institute http://www.cluteinstitute.com/ 
faster, cheaper or safer accessibility. ${ }^{19}$

Moving to the cloud "makes less relevant where work happens and where data is stored." ${ }^{20}$ While in theory institutions lose control of information they no longer house, many of them are drawn to cloud computing for the simplicity of offloading management responsibility — and its attendant headaches - for high-use operations such as data storage and email. According to the Campus Computing Survey, more than one-fifth of campuses (21 percent) have plans for cloud computing, up from 15 percent in 2010; use of the cloud is beginning with email and calendar functionality. ${ }^{21}$

Campuses have been slow to move operational and research functions to the cloud. Just 4.4 percent of Campus Computing Survey participants report that their campus has moved or is moving to cloud computing for administrative system services. ${ }^{22}$ Most confidential student, financial and HR information continues to be stored on in-house servers.

Key computing activities will be among the last to move to the cloud. As products and security improve, even mission-critical operations will migrate to lower-cost, higher-capacity computing in the cloud.

\section{Long-term technology policy}

Technology is on the leading edge of change at institutions of higher learning. Despite well-documented IT budget cuts at colleges and universities, leaders in higher education can harness this change by easing into relevant technology that best meets economic, social or administrative challenges.

Both social media applications and mobile devices have a relatively strong presence on campuses today, thanks to low entry barriers, shared infrastructure and costs, minimal management overhead, and immediate access to information. For a generation of hyperconnected students, social media applications and mobile devices are expected forms of interaction. Admissions personnel who answer to this demographic have embraced these technologies in order to drive marketing efforts and broaden communication channels.

Already most institutions are established on Facebook, LinkedIn and dozens of other social media websites that provide always-on communication channels for streaming campus news and delivering educational content and course updates. Faculty and staff aren't far behind, adapting these same channels to disseminate information about academic, social, safety and wellness, transportation and administrative services.

Large-scale digitization efforts have been primarily market driven, as well. As text becomes digitized elsewhere, institutions are aggressively catching up, converting print into bytes and libraries into study halls. Educators are planning curricula and research projects around the extraordinary amount of digitized information that is now available. Students care about access to information, forcing the higher education sector to focus on making sure they have the right tools to gain this access. The smooth integration of online learning and cloud computing requires long-range planning. Leaders in higher education should take the opportunity to learn about these technologies now in order to anticipate change and stand out from the competition.

To approach distance education strategically, leaders should take a look at what competitors are doing and find ways to adapt learning environments according to the image and competitive advantages the institution wants to promote. An action plan may be as simple as assigning to an individual or a committee the responsibility for selecting technological applications, determining the appropriate implementation method, and tracking progress toward IT goals. Similarly, leaders should ease into the cloud with a plan in mind, particularly when it comes time to

\footnotetext{
${ }^{19}$ Ibid.

${ }^{20}$ Hignite, Karla; Katz, Richard N; and Yanosky, Ronald. Shaping the Higher Education Cloud (EDUCAUSE/NACUBO white paper), May 2010.

${ }_{21}$ The Campus Computing Project. The 2011 Campus Computing Survey, October 2011. Available at www.campuscomputing.net/survey

${ }^{22}$ Ibid. 
address security concerns. This plan should satisfy the risk tolerance of trustees, while encouraging them to accept the cloud and keep the institution moving forward.

Institutions that view IT as a tool to further the mission of higher education - and institutions that have a plan in place for assessing and implementing relevant technologies — can create a purposeful learning environment for the next generation of learners.

\section{ACCESS AND AFFORDABILITY}

Larry Ladd, Director, Higher Education Practice, Grant Thornton LLP

Calls for making higher education more affordable continue to escalate, with President Barack Obama's most recent State of the Union address being a noteworthy example.

A college education is increasingly unaffordable for many students and their parents. The annual cost of a private college has grown from under 80 percent of per capita income to 112 percent since 1980, and the cost of a public college has risen from less than 40 percent to 49 percent. ${ }^{23}$ Average student debt per borrower at a private college was $\$ 22,300$ in 1999 - 2000, as compared with $\$ 26,100$ in 2008 - 09 (the most recent academic year for which statistics were available), according to the Federal Reserve. ${ }^{24}$

The federal government provides the bulk of undergraduate student aid through loans (43 percent), Pell grants (18 percent), grant programs other than Pell ( 8 percent), education and tax credits (4 percent) and work-study (1 percent). Of all undergraduate student aid, 6 percent comprises state grants. ${ }^{25}$ These aid programs are prime targets in government deficit reduction strategies and are unlikely to survive at their present levels, putting more pressure on affordability.

Although calls for government regulation of educational costs (or, alternatively, for incentives to reduce those costs, as President Obama has proposed) have intensified over the past decade, we believe that self-regulation of prices by colleges and universities remains the best solution.

\section{PLAN FOR DECLINING GOVERNMENTAL SUPPORT}

\section{Mary F. Foster, Managing Director, Higher Education Practice, Grant Thornton LLP}

Governmental support in the form of state appropriations, student financial aid, and grants and contracts has been declining for public universities and is likely to decrease for many private universities. Most state governments have been reducing their appropriations for public universities and have not increased tuition assistance programs for private universities.

Over the past decade, state governments in general have divested from higher education and shifted dollars to primary and secondary education. The divestiture by state governments is not just about competing priorities for state funding. It also signals the need for public universities to make their case to state governments for investing in high-quality, affordable college education that has solid student outcomes and proven economic benefits for the local municipality and for the state.

Although it has not declined for the past two years, federal funding for student financial aid is now under scrutiny by Congress and President Obama. The president's budget proposal to tie financial aid funding to tuition affordability is an extremely difficult issue for most private universities. The president's focus on job training and

\footnotetext{
${ }^{23}$ Ricketts, Lowell R. "Is a College Cap and Gown a Financial Ball and Chain?” Liber8® Economic Information Newsletter (Research Library of the Federal Reserve Bank of St. Louis), August 2011.

${ }^{24}$ Ibid.

${ }^{25}$ Baum, Sandy; Payea, Kathleen; and Cardenas-Elliot, Diane. Trends in Student Aid 2010 (College Board Advocacy \& Policy Center), p. 11, 2010.
}

(C) 2012 The Clute Institute http://www.cluteinstitute.com/ 
skills development programs, which would help the existing workforce remain employable and the unemployed find meaningful work, is not a core mission for the traditional four-year private college or university. If this shift in national focus is enacted in the upcoming budget, it will bring a reallocation of financial aid dollars from higherpriced four-year colleges to more moderately priced two-year colleges and technical schools. Even if this shift in funding priorities is temporary, its impact on four-year institutions, which require a consistent cohort of students during all four years, will be significant.

Federal funding for research has been bolstered in the past three years by American Recovery and Reinvestment Act (ARRA) funds and is not likely to grow in the foreseeable future. There is intense competition between the medical and nonmedical sciences for research dollars, and the allocation of appropriations among the National Institutes of Health, the National Science Foundation, and the Office of Naval Research will signal likely research priorities. For some universities, this will be good news; for others, the news will not be as hopeful.

Each university is left with determining what cuts in government aid to expect and which programs will feel the effects. Universities with well-established research projects and strong reputations will most likely not see a significant change in direct funding. However, universities that are seeking to garner a critical mass of research projects and grow their research programs may be more at risk of funding cuts. But that also depends on the fields of research that faculty are pursuing and who their partners are. Collaborative research projects with other institutions are viewed as a competitive advantage, and they also spread the risk of funding variability among several institutions.

Against this backdrop of uncertain or declining governmental support, and in the face of a national outcry about rising tuition prices, universities must plan for the future. Part of this planning must entail resisting these trends and fighting for government funding. But pleas for more funding will not be persuasive if they are not supported with hard outcomes data. This data needs to dispel the notion that universities are inefficient, high-cost operations that are unresponsive to employers' demands, consumers' pocketbooks and students' needs. The case also needs to be made that endowment funds are designed to serve the university in perpetuity; they are not rainyday funds as some would like to believe.

Perhaps the fundamental outcomes data is that which will help determine whether universities prepare students for a productive future that adds to the nation's economic growth and enables graduates to repay federal loans and live independently.

Of course, outcomes from private and public universities will be compared, and these comparisons are not without controversy.

Consider the first obvious issue: Is the tuition differential justified by the outcomes? While the top 10 percent of private universities may be able to justify tuition prices with differentiated outcomes, will the other 90 percent be able to do so? And what happens when public universities continue to raise tuition prices to offset cuts in state appropriations?

On the surface, the average policymaker or consumer believes these to be fair comparisons. However, the underlying dynamics of student readiness, university mission and values, and academic philosophy disturb these purportedly level comparisons between universities. Therefore, making the case for governmental support of higher education entails a reeducation of policymakers about the value of a degree - whether completed at a private university or a public one - along with a determination of whether the degree is affordable and can realistically be earned in four years or less. Unfortunately, affordability appears to mean parents' ability to pay based on tuition rates when they were in college. Tuition rates, even after discounts, are more than double those of 25 years ago, hence, the outcry against tuition prices and the level of debt that students have upon graduation.

If a private university is successfully graduating 90 percent of a cohort of students in four years and a public institution is doing so in six years, the higher tuition will likely be more than offset by the earning power of the student during the additional two years. However, that scenario assumes a comparable level of student debt. If the parents' ability to pay is not at least 50 percent of the private tuition rate, then the student will have a higher 
proportion of debt to earnings. Compare tuition of $\$ 40,000$ per year for four years to tuition of $\$ 17,000$ to $\$ 20,000$ per year for six years. The case for governmental support for private institutions may be even more difficult to justify if both private and public colleges are graduating 90 percent of their students in the same number of years. Then the price differential needs to be justified by net tuition paid and by the earnings differential and other student success factors.

The normal way to demonstrate value is through an assessment of on-time graduation rates, subsequent employment or entry into graduate programs in students' fields of study, career earnings that repay loans, research opportunities that enhance graduate applications, and certificate programs that help adult learners retool their skills while earning a degree. Other student success factors can include expedited job placement, internships, leadership roles that foster employment networks, paid graduate teaching or research activities, and entrepreneurial opportunities.

But those outcomes pertain only to the tuition pricing and financial aid components of governmental support. They may be persuasive to educators but not necessarily to funders. The biggest challenge is to demonstrate graduating a high percentage of freshmen in four years or less with debt loads that are commensurate with the earnings in their chosen profession. This will require a rethinking of net tuition prices for different majors, the provision of free or fee-based online courses that accelerate learning, the use of summer and winter sessions, and the pricing of tuition for unpaid internship semesters.

Research funding for those colleges and universities that are newer entrants into the world of laboratory research (wet research) will be harder to secure from the federal government and may be easier to obtain by garnering foundation and corporate support, and collaborating with larger institutions. Funding for written and published research (dry research) will not increase, and funders will be more attracted to collaborative studies. It would therefore behoove institutions to form a network of collaborative research partners and to identify emerging fields of research where the institution can be a subrecipient or subcontractor on various projects and the lead research institution on other projects. Mixing it up, so to speak, is also a good way to encourage newer faculty members to pursue wet and dry research projects. Research is important as a purely academic endeavor, but it takes on increased importance when it is one of the elements in demonstrating positive student outcomes.

Public universities face unique challenges with respect to state funding. During the past two decades, most states have either reduced the amount appropriated for public university operations or increased the appropriations at a level much lower than the increases in operating costs. Hence, at the end of 2011, state funding as a percentage of total university budgets was significantly less than it was 10 or 20 years ago. At the same time, some states have retained the authority to limit the tuition rate increases at their public universities, which represents a double revenue challenge for university administrators. For state officials, part of the policy debate over appropriations and tuition levels is about shifting the burden to parents to pay more for a public college education. Appropriations that support capital improvements for research facilities, along with technological and green infrastructure improvements, represent investments in the delivery of cost-effective education and real-time job creation. In other words, appropriations for these types of capital improvements help create jobs today and train people to succeed at jobs in the future.

Although the responses to the inevitable decline of governmental support are topics with which every administrator is familiar, the catalyst for making the case for governmental support of higher education - loudly, clearly and with demonstrable outcomes - should be the current federal and state budget crises we all face. It is easy to say the higher education model is broken when one has not really seen how the model works or measured the ultimate outcomes. 


\title{
FEWER OPPORTUNITIES FOR REVENUE GROWTH, GROWING CRITICISM OF CURRENT OUTCOMES DRIVE THE NEED FOR PARADIGM SHIFTS
}

\author{
Mary F. Foster, Managing Director, Higher Education Practice, Grant Thornton LLP
}

There are few universities that will see new revenue streams in the near future. Large research-based universities may experience spikes in technology transfer revenue, and institutions with sizable endowments are witnessing a rebound in their investment portfolios. But higher endowment earnings will be offset by lower spending rates - a lesson learned from the recent recession - so there will not really be new revenues for the operating budget. Furthermore, governmental support is generally on the decline; although that support is holding steady in some cases, increases in funding are not likely.

So the standard-bearers of university revenues are tuition and philanthropy. Large philanthropic gifts come with strings attached, and tuition increases come with public outcry and government threats. So for $2012-13$, revenues will be driven by student volume, corporate and alumni giving, and competitive foundation and government grants. Of course, there is always the ability to look at facilities in a new light: Can revenues be generated by leasing out garage space, rooftops, classrooms, athletic facilities, labs and student housing?

But the critical paradigms that are shifting are about rethinking the delivery of education and making better use of existing assets and infrastructure. Hospitals and community colleges have been evolving to 24/7 operations so that more patients and students can be served in a high-quality and cost-effective manner. Businesses have been doing more with less this past decade. Four-year colleges and universities are seen by business executives and government as the last vestiges of a minimal workweek with luxury accommodations - in essence, costly and not accountable for the productivity of students or faculty. It doesn't matter if that perception is fact-based or not — it drives public opinion and hence, policy decisions.

Let's consider the recent building programs under way at many universities. The terms "adaptive reuse" and "redevelopment" need to be integrated into institutions' vocabulary for describing capital and building programs. The best green initiative is not constructing a new building, but rather reusing and expanding what is there. The greenest development strategy is infill development, not building on greenfield lands. Those who pay the bills for education - government, business and parents - see new buildings on expanded campuses as expensive luxuries. Although new facilities may be needed, the scope and breadth of the building campaigns this past decade have been astonishing. And the prevailing belief is that these campaigns are driving up the cost of education at four times the rate of inflation. ${ }^{26}$

This view may inform future building programs, but as of now there are new buildings on college campuses that can serve students in a more cost-effective manner. The challenge is to align facilities with curricula and the needs of 21st-century learners. First of all, not all learners will be traditional 18- to 24-year-old college students. Adult learners are a growing population that needs access to certificate programs, new degrees, specialized faculty advising and 24/7 online convenience. According to the Department of Education's National Center for Education Statistics, the market for adult learners will be the fastest-growing market for the foreseeable future. This market rose by 32.6 percent between 1995 and 2009 and is expected to rise by another 18.8 percent between 2009 and $2020 .{ }^{27}$ The recession accelerated this demand for adult education, with access and affordability being the critical factors. The adult learner needs flexibility, support structures and nontraditional hours. And the market for adult learners can cover the costs of new facilities.

Another leading perception is that higher education is not accountable for graduating highly skilled students on time. This criticism stems from the six-year graduation statistics that have become the norm, as well as

\footnotetext{
${ }^{26}$ Cronin, Joseph Marr, and Horton, Howard E. "Will Higher Education Be the Next Bubble to Burst?" The Chronicle of Higher Education, May 22, 2009; the quotation comes from

Phyllis T.H. Grummon's contribution to Trends in Higher Education, Volume 6, No. 2, 2010 (Grummon's article cites Elizabeth Redden in "An Academic Revolution," Inside Higher Ed, July 7, 2009).

${ }^{27}$ Hussar, William J., and Bailey, Tabitha M. Projections of Education Statistics to 2020, September 2011.
} 
the low levels of interpersonal and writing skills that graduates are seen to possess. The other elements in student success - or lack of success - that have come under attack are the poor quality of faculty advisement and the dearth of job readiness skills. These are areas where the use of social media, coaching, Skype and real-world interactions can merge. These are also areas that are ripe for interactions between the adult learner and the traditional learner. Expanding the opportunities for the traditional student to interact with the business-savvy adult learner will leverage the efforts of faculty advisers.

The challenge is to align facilities. Universities must be held accountable for the alignment of faculty and lab resources with the number of students requiring those courses. If new faculty line items or lab spaces cannot be added to the budget, then the use of what already exists must be expanded. With the correct use of technology, flexible spaces and in-classroom teaching, a class can serve 300 students as easily as 30 students.

The point is that colleges and universities, especially four-year institutions, need to respond to the perceived inadequacies of the educational system in order to stave off the criticisms of cost versus outcomes. Outcomes must improve or tuition revenue will be eroded by the lack of government and business support.

There is another critical paradigm that is shifting: accountability by school within a university for balancing its budget based on its own revenue. Though this may be fraught with political challenges, it drives front-line management accountability for course offerings, student retention and graduation rates, faculty advisement, and cost control. This approach also encourages alumni outreach and visible research, both of which are revenue generators.

Heightened accountability, increased pricing transparency and improved student outcomes are being demanded by the public. The higher education sector is more than capable of responding to these demands in an effective and innovative manner.

\section{A NEW ERA IN COMPENSATION}

Michael J. Monahan, National Practice Leader, Not-for-Profit and Higher Education Compensation and Benefits, Grant Thornton LLP

The higher education community continues to seek out ways to respond to ongoing pressures being imposed upon leadership by regulators, donors, alumni, faculty and other stakeholders. The best protection against allegations of unreasonableness remains the implementation of sound governance practices in the compensation decision-making process.

\section{Higher education compensation decision-making process}

A clear and formal statement of purpose designating responsibility and authority is an essential element of the decision-making process for compensation committees. No matter who drafts the statement of purpose, the reality of why a committee has been formed, what responsibility it has in relation to the success of the institution, and what authority the committee and its members have to make and implement decisions and fulfill the institution's purpose should be understood by board members and management alike.

Following is a sample statement of purpose for a compensation/human resources (HR) committee:

The compensation/HR committee (the committee) of Prestigious University (Prestigious) is a critical component of the overall governance role that the board of trustees has in relation to the ongoing leadership, decision-making and success of Prestigious. This committee will consist of five members of the board of trustees, each of whom is experienced in supporting complex, effective and compliant compensation, benefits, HR and/or succession planning programs in higher education or a similar environment. Each member receives a three-year appointment to the committee from the chairman of the board of trustees.

The committee is responsible for the oversight, administration and design of the various total compensation programs offered by Prestigious to its employee constituencies; serves as an adviser and partners with senior 
leadership in developing optimal HR strategies; oversees the administration of performance management programs; and evaluates, on at least an annual basis, the total compensation provided to the executive leadership team of Prestigious by comparing the institution's total compensation offerings with those of similar institutions in a manner that is consistent with federal regulations. In addition, the committee is responsible for administering the performance evaluation process for the president of Prestigious and for establishing an effective succession planning program across the institution's leadership.

The committee has the authority to hire advisers in relation to its responsibilities and is specifically charged with setting annual performance metrics for the president and the other members of the institution's leadership team. Those positions may vary from year to year and time to time, but the leadership team will typically include the provost, the chief financial officer, the general counsel, the chief investment officer, the chief technology officer, the athletic director, the dean of the medical school, the dean of the law school and the dean of undergraduate studies. The committee will also have the authority to establish compensation levels, benefit offerings and employment conditions (e.g., terms of employment contracts, severance programs and deferred compensation arrangements) for the president and the other members of the leadership team on an annual basis, subject to the ability of the full board to be informed of any decisions that are made regarding the conditions of employment and/or tenure of the president of Prestigious.

The committee in its sole discretion may from time to time delegate its responsibilities to a subcommittee or special committee of the board, provided that authority for decision-making remains with the full committee. Examples of subcommittees are a president's compensation committee, a physician compensation committee and a faculty compensation committee.

\section{Incentive compensation and creating a pay-for-performance culture}

Implementing a pay-for-performance culture remains challenging for many colleges and universities across the United States, yet the adoption of formal incentive compensation plans continues.

As more institutions formalize the structure and operation of their compensation committees, the need for rigor in calibrating incentive compensation can present challenges. That said, following robust governance practices will lay a solid foundation for sound programs.

Below are some best practices:

- $\quad$ Keep the business purpose rule in mind - Effective compensation committees not only determine appropriate salaries and incentives, but also establish the link between total compensation and the institution's mission and values.

- Establish the rebuttable presumption of reasonableness - The amounts and design of total compensation packages provided to a broad constituency of leadership individuals (e.g., disqualified persons, key employees) need to be reflected upon by appropriate decision-makers. Comparable external market data should be examined, and a formal process should be followed.

- $\quad$ Consider the stakeholder optics - Compensation decisions should take into account the effects that current or projected Form 990 disclosures, particularly those concerning salaries and incentives, are likely to have on stakeholders. The compensation committee and the board should be able to anticipate inquiries by preparing responses.

- Maintain collaboration among leadership functions - Through effective partnerships between their finance and HR departments, colleges and universities can deepen their understanding of how compensation and benefits programs can change the institution, help it deliver strong results, and facilitate operational success. 


\title{
GOVERNMENTAL SCRUTINY THROUGH TAX ENFORCEMENT
}

\author{
Daniel Romano, Partner-in-Charge, Not-for-Profit Tax Practice, Grant Thornton LLP
}

There is seemingly a new problem to tackle every day in the world of higher education - budget issues, tuition discounting, liquidity, opening a school, or perhaps starting a study-abroad program. Higher education institutions are facing all these issues and a plethora of others, including tax compliance matters. After all, colleges and universities have been granted tax-exempt status, and to maintain that status, they must comply with myriad rules and regulations at the federal, state, local and international levels.

In the federal tax compliance arena, the most common issues involve unrelated business income (UBI). This is especially important because UBI audits are a revenue generator for the federal government. The IRS has UBI examinations under way that stem from its recently completed Colleges and Universities Compliance Project. That study revealed that many respondents conducted UBI-producing activities but did not report them as such. In addition, most of those that reported UBI had net losses from these activities. As a result, the IRS has sharpened its focus on UBI-producing activities, checking into whether institutions are reporting their UBI appropriately and whether the expense allocations made for those activities truly bear a direct and causal relationship to them. Further, the IRS is taking the position that when activities result in losses in three out of five years, institutions cannot use those losses to offset gains produced by other UBI activities. Because of this sharpened focus, we have seen many institutions undergo a review of their UBI activities in preparation for a potential IRS examination. We expect this trend to continue throughout 2012.

The IRS has also sharpened its focus on employment taxes. Employment tax examinations can be performed by the Exempt Organizations Unit or the Employment Tax Unit, which have similar objectives. Areas of concentration include excessive compensation, especially as it relates to executives (i.e., intermediate sanctions); the taxation of benefits, including perquisites provided to key employees; and worker classification.

Form 990 is a major source of information for the IRS in selecting institutions for examination. What is disclosed on that return, especially in the compensation section, can greatly increase an institution's chance of being audited. Does your institution pay for companion travel (which the IRS very strongly feels is taxable)? Do you provide personal services such as maid service for the president? Do you pay for golf or country club dues? All of these perks should be considered taxable compensation unless they have a clearly defined business purpose that can be supported and documented.

In the worker classification arena, the IRS follows established guidelines in determining who has control of the workers' duties and the relationships that exist between the institution and the workers (including the longevity of those relationships). Often it is the failure to document these relationships that results in adverse determinations by the IRS. Do you have contracts in place that clearly set forth the job specifications and the financial aspects and terms of each relationship? Can the institution document that the workers hold themselves out to others to provide similar services? These are some ways to bolster your position when treating an individual as an independent contractor. In looking at worker classification, the IRS chooses a test sample and then extrapolates the results across an institution's entire population. Because of this sampling technique, adverse findings in the tested sample cause taxes and penalties to add up quickly. Many institutions have revised their employment tax practices to mitigate their risk. We recommend taking such action.

Foreign tax compliance is still another area of sharpened IRS focus. There has been much to-do over Foreign Bank and Financial Accounts filings over the past two years, but what has become more of a burden for higher education institutions are the compliance requirements relating to foreign investments. If an institution has offshore investments or has investments in a domestic partnership that invests offshore on the university's behalf, there is likely some reporting to do. Each form (e.g., Forms 926, 8865, 5471) has a capital contribution threshold amount and/or an ownership percentage threshold that must be considered in determining whether filing that form is called for. And the forms carry steep penalties for failure to file - penalties that start at $\$ 10,000$ per form. With alternative investment portfolios growing, many of which are concentrated in foreign investments, there is a compliance burden with respect to U.S. taxation that needs to be addressed. 
While the ultimate intent of these filings is to capture hidden taxable income, higher education institutions may be penalized for failure to comply with the requirements even though the income may not be taxable. Some members of Congress want to take a closer look at the taxability of these investments. In the future, Congress may decide that all foreign investments should be taxed as UBI. Institutions should create information-gathering procedures for determining whether they have foreign filing requirements and how to file the appropriate forms. Tax-exempt organizations must attach all such forms to Form 990-T, regardless of the need to file a Form 990-T under other circumstances.

Not that the IRS is the only agency stepping up its scrutiny; state and local governments are also taking a closer look. Over the past two years, many states have begun to more critically examine governance and compensation practices at not-for-profits. Some of these states adopted or proposed laws to place a cap on executive compensation that would be reimbursed from state funds and to eliminate funding for institutions with poor compensation practices. This trend is likely to continue as states struggle with budget constraints.

Many states are also aggressively stepping up their examination of UBI activity. For instance, they are looking at the need for colleges and universities to file returns and pay taxes in states in which they may not operate, but in which they do receive UBI from limited partnerships. This scrutiny, too, will likely sharpen in the coming years.

We noted a considerable rise in the number of municipalities imposing either payments in lieu of taxes or service fees on colleges and universities because these institutions benefit from local fire and police protection, water and sewage operations, and similar municipal services. These "voluntary" payments are negotiated with each institution and may be based on the amount of property tax that would have been assessed, the number of hospital beds, or some other quantifier. Whatever method is used, the payments are usually not so voluntary.

And we have seen an uptick in the review of property tax exemptions by local governments, with stricter examination of applications and more stringent assessments of tax on property rentals.

We believe that tax-related scrutiny will sharpen as the economy continues its struggle to recover. Taxexempt entities are being looked at as a fresh source of tax revenue and a sector that has benefited from government largesse. A well-thought-out compliance program is necessary to address these and other areas so that the university's tax positions are well-supported in the face of challenges by the IRS or other taxing authorities.

\section{SUSTAINING AN ETHICAL CULTURE REMAINS CRITICAL TO YOUR SUCCESS}

Larry Ladd, Director, Higher Education Practice, Grant Thornton LLP

"It takes 20 years to build a reputation and five minutes to destroy it," a quote attributed to Warren Buffett, is a stark reminder of the fragility of a reputation and of the vigilance that is required to protect that reputation. For colleges and universities, reputation is the asset that matters more than any other. It represents the outcome of a strong academic program, excellent faculty, high student demand and many other factors. But a reputation can be damaged quickly with one incident, as we have learned from the recent events at Penn State.

Ethical behavior comes from a strong culture of ethics where the standards are clear, appropriate programs are in place, and both the standards and programs are reinforced by the examples set by the institution's leadership (i.e., its governing board and senior management).

There are few surveys or measures of ethical behavior in higher education institutions or in other not-forprofit organizations. The most recent and comprehensive was the National Nonprofit Ethics SurveySM conducted by the Ethics Resource Center in 2007. The survey found that not-for-profit organizations (including higher education institutions) have the highest ethics standing of any industry. However, it also found that integrity is eroding in the sector, with misconduct - especially fraud - on the rise. ${ }^{28}$

\footnotetext{
${ }^{28}$ Harned, Patricia J.; Hajiyev, Eyyub; Hartz, Michelle; Kelley, John C.; Lang, Katie; and Gabriel, Rielle Miller. 2007 National Nonprofit Ethics Survey, 2008. 
The Ethics Resource Center survey found that governance makes a substantial impact. ${ }^{29}$ Good governance increases the likelihood of ethical behavior, and poor governance compromises organizational ethics - which is another way to say that an appropriate tone at the top (as shown by behaviors, as well as rules) is critical to a strong ethical culture. The survey noted that well-implemented ethics programs can decrease the incidence of misconduct. ${ }^{30}$

"What seems to matter most," the report concludes, "is the extent to which ethics is woven into the fabric of everyday work life and decision-making, beginning at the top and moving throughout the institution. A commitment to ethics that engages all employees at all levels and incorporates ethical considerations into operational decisions is critical to reducing misconduct and [retaining] the good will of the public" (emphasis added). ${ }^{31}$

The past year has seen its fair share of embarrassing disclosures. Presidents have been discovered to have committed forgery or misrepresented their degrees. Administrators have been charged with embezzlement or other forms of financial misconduct. Colleges have reported distorted information about the SAT/ACT/LSAT scores of their students or the employment records of their graduates. Whistleblowers have been fired. And at Penn State and other universities, issues of misconduct by coaches have arisen, leading in Penn State's case to the firing of the president and a longtime head coach.

Of course, some ethical issues are clear-cut from a legal — or at least a moral — standpoint; examples of obviously unethical behavior include perpetrating fraud, lying, falsifying records, displaying overt racism or committing other hate actions, and invading privacy. However, it is in the gray areas, where values conflict, that trustees and administrators are most challenged. (More on the gray areas later.)

There are six key elements involved in creating a culture that supports ethics:

Formal policies and procedures. The ethics policies of every institution of higher learning need to be documented explicitly, especially in areas such as HR, student conduct and accounting. A code of ethical conduct should be established, along with conflict-of-interest, whistleblower and transparency/disclosure policies. Colleges and universities should also consider implementing - if they don't already have them in place - a separate code of ethical conduct and a conflict-of-interest policy specifically for senior management and key employees, and a third set of ethics and conflict-of-interest policies for trustees. In all these cases, certain issues pertinent to reporting, to disclosure, and to professional affiliations merit explicit articulation in policy. For CPAs working within a college or university, specific sections of the AICPA Code of Professional Conduct also apply.

Monitoring. While written policies are important, equally important are consistent procedures for monitoring compliance with those policies. Monitoring procedures should include effective internal controls, periodic signing (or electronic acknowledgement) of policies, and prompt actions when issues arise. Measuring employee beliefs and attitudes about the ethical culture of an institution is also important. Anonymous surveys whose results are publicized and acted upon can be an effective way to measure employee attitudes toward ethics.

Communication. The mantra for any trustee or senior administrator is "communicate, communicate, communicate." Speeches, blogs and all other communications should consistently include references to ethical standards and conduct. Issues that arise should be used as positive examples, providing the basis for teachable moments within the institution. Make certain to honor those who are reporting misconduct. And it's always wise to avoid any behavior that wouldn't look good under a media spotlight.

Leadership. The president, trustees and senior management all need to lead by example, consistently following the highest standards. Exceptions to stated policy for so-called special circumstances are toxic. When issues arise, the institution's leadership needs to take responsibility for making difficult decisions. It's also important to be transparent about organizational performance, to keep promises, and to make decisions openly.

\footnotetext{
${ }^{29}$ Ibid.

${ }^{30}$ Ibid.

31 Ibid.
}

(C) 2012 The Clute Institute http://www.cluteinstitute.com/ 
Consistency. Policies and practices need to apply uniformly throughout the institution. Exceptions such as management overrides and side agreements have a corrosive effect on the culture. Everyone in the institution should be treated in the same fashion with respect to the same issues.

Accountability. Everyone in the institution must also be held accountable for his or her conduct. It is a serious mistake to overlook or excuse conduct that is inconsistent with the ethical standards of the institution - as Penn State learned to its detriment. Swift and fair action is necessary when misconduct occurs. Performance that supports high ethical standards, including performance that reinforces an appropriate tone at the top, should be visibly rewarded. And when wrongdoing does occur, institutions should accept responsibility.

But it's in the gray areas where the real challenges lie.

Here are some examples:

Conflicting loyalties and values. It is important to be loyal to your employer, but when do you speak up? Sometimes speaking up creates the appearance of disloyalty but will serve the institution better in the long run. Loyalty to your supervisor is also important, but where is the line between loyalty and dishonorable behavior? In another example, some universities explicitly or implicitly support religious values that may conflict with your own values. What do you do when you are on the wrong side of the conflict?

Actual versus perceived issues. What is unethical to one person isn't necessarily unethical to another. One or more constituencies may perceive behavior to be unethical even when it is not. When it is your reputation you are protecting, you must avoid even the appearance of acting unethically.

Transparency versus keeping quiet. Many colleges and universities don't publicize minor instances of fraud or other ethical violations for fear of incurring reputational damage. If you become aware of an ethical issue, ask yourself this question: Can too much transparency about this issue erode confidence in the institution?

Budgeting and financial reporting. Intentionally misstating financial information is obviously wrong. But what about forecasts that might be too optimistic or too pessimistic, plans that don't show all the assumptions, or financial information that camouflages bad news?

Marketing. Truth in advertising is important. Do your marketing materials portray the institution accurately?

$H R$. Are hiring, evaluating and firing based on performance, or are other factors involved? If so, are they explicit and consistent with the institution's mission, or do they imply favoritism or inequality? Have both the appearance and the reality of due process been maintained? For example, how do you handle the conflict between privacy and disclosure when there is a grievance?

Globalization. How do you behave with respect to programs and campuses in countries whose cultural values are different from yours?

Corporate social responsibility. Few trends in higher education have been more pronounced than the growing sense of corporate social responsibility. For instance, programs encouraging environmental sustainability are in place on almost every campus in the United States, with websites documenting institutions' progress and demonstrating their commitment. There is no better indicator of the greening of sector leadership than the American College \& University Presidents' Climate Commitment. ${ }^{32} 32$ But how far should these programs go? Must cost savings always be a factor? What happens when cost exceeds savings? Fostering diversity is another key component of an institution's social responsibility, not only as a justice issue, but also as an educational issue. But how far should the institution go to promote a diverse population? Another element of social responsibility is being a good neighbor to those who live and work in close proximity to the campus, but what happens when institutional priorities clash with neighborhood interests? Lastly, socially responsible investing has been a growing practice among institutions since

${ }^{32}$ See www.presidentsclimatecommitment.org for more information 
the boycott of South Africa in the 1980s, but again, there is sometimes a conflict between investing only for financial gain and investing for a combination of financial and social gain.

Acting on an issue. Even the question of how to act when you perceive an ethical violation is a gray area. Do you go up the chain of command? Do you follow the whistleblower policy or go to the audit committee? Do you resign if the issue hasn't been resolved to your satisfaction? Do you keep the issue private, or do you publicize it?

Sustaining an ethical culture on campus requires work from everyone, but especially from senior leadership, which must model and reinforce the best possible behavior and help everyone navigate the uncertainty that sometimes occurs. But the reward is great: an institution with a strong reputation and a bright future.

\section{GLOBALIZATION AND THE INTERNATIONAL STUDENT}

\section{Mary F. Foster, Managing Director, Higher Education Practice, Grant Thornton LLP}

Notwithstanding current criticisms of U.S. colleges and universities, these institutions still represent the world's preeminent educational system. This international standing will continue as long as U.S. universities maintain their reputations as preeminent leaders in research and comprehensive education. However, both China and the UK currently rank universities globally; China publishes the Shanghai Jiao Tong University Ranking of World Universities, and Britain publishes Times Higher Education-QS World University Rankings. The European Commission on Education and Culture has funded a project to create a global university ranking system that would rival China's and the UK's university ranking system. Since U.S. universities benefit from substantial enrollment of foreign students at their domestic and foreign campuses, university ranking systems developed by other countries are important data to be analyzed and understood.

The Society for College and University Planning notes that the number of postsecondary students increased worldwide from 100 million students in 1998 to 150 million students in 2009, according to United Nations Educational, Scientific and Cultural Organization estimates ${ }^{33}$ Chronicle Research Services reports that according to one study, the number of people looking for higher education around the world will grow to 200 million by $2025 .^{34}$ And a study performed by an international consulting firm indicates that demand for education in which learners travel from their country of origin will rise from 2.1 million students in 2005 to 3.7 million students by $2025 .^{35}$ How many of these students come to the United States will depend on price and reputation, and on competitive recruiting efforts by Canada and Britain, which are the next most popular countries for study-abroad programs.

Following are some of the major trends in international enrollment at U.S. universities:

- The number of international students enrolled in U.S. universities rose 10 percent per year from 2005 through $2008,{ }^{36} 3$ percent in 2010 , and 6 percent in $2011 .^{37}$

- The five-year rate of increase is 38 percent for undergraduates and 39 percent for graduate students. ${ }^{38}$

- $\quad$ The five largest sources of international students who travel to the United States are India, China, South Korea, Japan and Canada. ${ }^{39}$ However, the price for an American education is more difficult to pay during a worldwide economic downturn, and under current circumstances, the growth in international enrollment is harder to predict.

\footnotetext{
${ }^{33}$ Grummon, Phyllis T.H. Trends in Higher Education, Volume 6, No. 2, 2010 (article cites Elizabeth Redden in "An Academic Revolution," Inside Higher Ed, July 7, 2009).

${ }^{34}$ Van Der Werf, Martin, and Sabatier, Grant. The College of 2020: Students, June 2009 (report cites Beth McMurtrie in "Global Downturn Is Not All Bad News for International Educators," The Chronicle of Higher Education, March 6, 2009).

35 Ibid.

${ }^{36}$ Ibid.

${ }^{37}$ Grasgreen, Allie. "Report Shows Study Abroad, Foreign Enrollment Rising," Inside Higher Ed, November 2011.

${ }^{38}$ Ibid.

${ }^{39}$ Van Der Werf, Martin, and Sabatier, Grant. The College of 2020: Students, June 2009 (report cites Beth McMurtrie in "Global Downturn Is Not All Bad News for International Educators," The Chronicle of Higher Education, March 6, 2009. Grasgreen, Allie. "Report Shows Study Abroad, Foreign Enrollment Rising," Inside Higher Ed, November 2011.
}

(C) 2012 The Clute Institute http://www.cluteinstitute.com/ 
- $\quad$ Enrollment from India is hampered by stricter lending standards in that country. ${ }^{40}$

- The declining value of the South Korean currency has impacted short-term enrollment from that country. ${ }^{41}$

- While India has the largest number of inbound students studying in the United States, the biggest rate of growth in international student enrollment continues to come from China. ${ }^{42}$ According to the May 31, 2009, issue of University World News, China's Ministry of Education was providing support for 5,000 graduate students to study abroad. ${ }^{43}$ However, China is aggressively investing in its own higher education system, and recruiting foreign science and engineering researchers. China now ranks fifth as the most popular destination for Americans studying abroad, according to the Aug. 31, 2009, issue of The Chronicle of Higher Education, ${ }^{44}$ and fifth in 2010 , according to Inside Higher Education. ${ }^{45}$

- $\quad$ According to The Academic Executive Brief, Taiwan's Ministry of Education is making a $\$ 50$ billion-plus investment in Taiwanese research-intensive universities. ${ }^{46}$

The lesson to be learned for universities seeking to expand their international student base is that students from wealthier families choose high-prestige universities and pay the going rate, while students from less wealthy families look for affordability and institutional aid.

So while there appears to be a growing population of future students for U.S. universities, a contraindicator may occur if U.S. universities do not deal with student graduation rates and employment skills. To address learning outcomes, the European Higher Education Area has implemented three-year bachelor's degrees. ${ }^{47}$ Naturally, American policymakers such as U.S. Senator Lamar Alexander from Tennessee are wondering why U.S. higher education has not moved to the European three-year model. ${ }^{48}$

With the worldwide growth of the student population that is eligible to enroll in higher education, U.S. universities continue to invest in campuses overseas. Study-abroad programs will be impacted in those European countries that are struggling with austerity and debt reduction measures. However, currency fluctuations, recruitment efforts by foreign education ministries, and the worldwide economic slowdown (even China is not immune) make China, India and Taiwan attractive places for overseas campuses.

\section{THE PRESIDENT MUST LEAD, NOW MORE THAN EVER}

\section{Larry Ladd, Director, Higher Education Practice, Grant Thornton LLP}

The firing of Penn State's president brought attention to the presidential role, however unwelcome or unflattering that attention may have been. For certain, it shows how a president is the one individual who is ultimately held accountable at any college or university. It also shows that the buck stops with the governing board, which must insist on accountability. We hope that the Penn State situation is unique and that few presidents are confronted with such dramatic circumstances. But there is another lesson to be learned from the Penn State incident - namely, that creating and sustaining an ethical culture is one of the foundations of a president's role.

\footnotetext{
${ }^{40}$ Van Der Werf, Martin, and Sabatier, Grant. The College of 2020: Students, June 2009 (report cites Beth McMurtrie in "Global Downturn Is Not All Bad News for International Educators," The Chronicle of Higher Education, March 6, 2009).

${ }^{41}$ Ibid.

${ }^{42}$ Grasgreen, Allie. "Report Shows Study Abroad, Foreign Enrollment Rising,” Inside Higher Ed, November 2011.

${ }^{43}$ Schrock, John Richard. "CHINA: Ministry recruits 2,000 foreign scholars," University World News, May 2009.

${ }^{44}$ Parry, Marc. "Professors Embrace Online Courses Despite Qualms About Quality,” Chronicle of Higher Education, August 31, 2009.

${ }^{45}$ Grasgreen, Allie. "Report Shows Study Abroad, Foreign Enrollment Rising," Inside Higher Ed, November 2011.

${ }^{46}$ Feng, Da Hsuan. "A new Taiwanese university system begins to take shape amid major societal shifts," The Academic Executive Brief.

${ }^{47}$ Grummon, Phyllis T.H. Trends in Higher Education, Volume 6, No. 2, 2010 (article cites Elizabeth Redden in "An Academic Revolution," Inside Higher Ed, July 7, 2009).

Grummon's article cites Clifford Adelman in "The Bologna Process for U.S. Eyes: Re-learning Higher Education in the Age of Convergence," Higher Education Policy, April 2009.

${ }^{48}$ Alexander, Lamar. "The Three-Year Solution," Newsweek, Oct. 17, 2009. 
To be successful, presidents of colleges and universities need to focus primarily on three things: strategy, relationships and accountability. Everything else can be delegated to others as long as the president monitors the performance (and enforces the accountability) of those to whom the tasks have been delegated and expects them to exhibit the highest standards in that performance.

Why strategy, relationships and accountability? Because those three factors will make or break the institution's growth and survival, and are what the president has the most control over. (Incidentally, making the "big asks" of fundraising can be placed within the relationship category.)

Strategy is key. The president is best-positioned to scan the horizon of social, cultural and economic trends, and to identify those opportunities that most closely match the strengths of the college or university he or she leads. A president is also best-positioned to keep everyone's eye on maintaining an institution's strategic position, including its reputation for upholding the highest ethical standards.

The opportunities awaiting presidents are abundant. The presidents who know which opportunities to seize and which to pass up are those whose institutions will thrive in the years ahead. Successful presidents will take the lead in how their institutions respond to issues involving the digital revolution, distance education, access and affordability, ethics and governance, globalization, and resource constraints.

A recent report by Public Agenda ${ }^{49}$ shows that trustees look to presidents for leadership and are not inclined to exercise that leadership on their own.

Relationships are also key. The successful president maintains relationships of communication and trust with all the important constituencies of the institution, including alumni, major donors, faculty, staff, students and their parents, and community and political leaders. Presidents can achieve their goals only by working with others, for it is the others who will choose whether to follow the president's lead or obstruct the president from accomplishing any objective.

Accountability is necessary. As the Penn State incident demonstrates, presidents are accountable to their boards. Boards must make that accountability structured and effective, setting measurable objectives and assessing performance consistently. Presidents must do the same with their vice presidents, helping establish a tone of high expectations throughout the institution.

According to a 2007 report $^{50}$ by the American Council on Education (ACE), the average age of university presidents rose from 52 in 1986 to 60 in 2006. Based on this information, it is likely that we are, or soon will be, in the midst of a significant transition in leadership among college and university presidents.

Recognizing the need for presidents to be prepared, ACE recently formed the Institute for New Presidents ${ }^{51}$ to help aspiring or newly appointed presidents gain vital skills and knowledge. The Institute for New Presidents joins a growing number of such programs run by Harvard, the Council of Independent Colleges and other organizations.

These organizations all understand that the presidency is no place for on-the-job training. One's own experiences, and lessons from others' experiences, are critical to success.

\footnotetext{
${ }^{49}$ Immerwahr, John; Johnson, Jean; Rochkind, Jon; DuPont, Samantha; and Hess, Jeremy. Still on the Sidelines: What Role Will Trustees Play in Higher Education Reform? Public Agenda, December 2011.

${ }^{50}$ American Council on Education. The American College President 2007 Edition. See

www.acenet.edu/Content/NavigationMenu/ProgramsServices/CPA/Executive_Summary.htm.

${ }^{51}$ See

www.acenet.edu/AM/Template.cfm?Section=Press_Releases2\&TEMPLATE=/CM/ContentDisplay.cfm\&CONTENTID=43465
}

(C) 2012 The Clute Institute http://www.cluteinstitute.com/ 


\title{
IT'S NEVER BEEN MORE IMPORTANT FOR THE BOARD TO ASK THE RIGHT QUESTIONS AND MONITOR STRATEGIC PLANS
}

\author{
Mary F. Foster, Managing Director, Higher Education Practice, Grant Thornton LLP
}

Perhaps the most important role of the governing body is to ask the right questions of university leadership about the stewardship of the university's brand, its financial resources, its intellectual capital and its student outcomes. Ensuring the university's ability to survive and thrive with sound management and prudent stewardship is the fundamental responsibility of any governing body. In order to carry out this charge effectively, the governing body needs a framework against which to pose these questions. University leadership also needs this framework to articulate its plans and goals to the governing body. This framework must express the strategy and measurable goals of the university, with the emphasis being on measurement and outcomes.

The business of higher education is rapidly evolving — and yes, this is a business. Academic programs, mission statements and strategic plans must be rooted in business principles. This is not intended to imply that mission statements and strategic plans must focus on profit principles and growth goals alone, but rather that they must provide a road map for strategic investments in academic programs, student outcomes, facilities, faculty, research, technology and the university's brand. The higher education sector will never return to the way business was done at the turn of the 21 st century. The sector is undergoing a tumultuous transformation, whether welcomed or not, and this transformation requires that clear choices be made about some of the most fundamental aspects of university life.

Financial measures are important, of course. But those measures will not inform the university's response to a marketplace that requires institutions to have distinguishing characteristics if they are to achieve long-term success. At its core, the university's mission of educating students hasn't changed. However, everything about how this is done is changing, and universities must determine their unique vision for engaging in the delivery of their academic mission. This vision articulates for students, faculty and stakeholders the type of educational experience that the university will deliver. The strategic plan should address priorities for undergraduate and graduate curricula, pedagogies for delivering academic materials, venues for student-faculty engagement, and goals for student graduation and employment outcomes. The strategic plan should also address competitive rankings, faculty mentoring and achievement, intellectual property and publications, engagement with the local economy, and responses to new industries and national economic drivers.

The advancement of technology has the ability to change your responses to basic questions: Who are your students? Who are your faculty? What are your facilities? What are your majors and degrees? And who are your researchers? These changes must be considered as the university's vision and strategy are established or updated.

Establishing (or reestablishing) a unique strategic direction for your college or university - a direction that sets you apart from your peers - requires the engagement of stakeholders across the university. It cannot be solely a top-down plan. If it is to be actionable, it must be viewed as a strategic vision that encompasses the entire university, creating alignment among schools and departments, providing for investments in research and teaching, setting priorities for technology, and articulating a plan to engage the 21st-century learner. The strategic direction must be trackable and the specific actions measurable. Everyone from administrators and faculty to leadership and the governing body must know the direction in which the university is heading, and the priorities and actions needed to get there. It must drive how choices are made and how the performance of faculty and administrators is evaluated. The measures that enable this tracking and evaluation must be synthesized into reportable metrics that are shared with the governing body and with campus leadership.

The governing body has an important role to play in understanding and assessing whether the metrics truly communicate the health and achievements of the university and the challenges that are impeding the attainment of its strategic goals. It is because of the importance of the governing body's role that strategic committees, ad hoc specialty committees and board retreats have become a necessity. 
As the strategy unfolds, management and the governing body will be required to coolly and astutely measure opportunities against the institution's vision and goals. Many times, behaving opportunistically is confused with behaving strategically. But there is an objective way to differentiate between the two. An opportunity must support the achievement of the vision and strategic plan as adopted. If it creates a modification to the strategic direction, whether in terms of the university's timing, its readiness, its priorities or its outcomes, then it is opportunistic and not a strategic initiative. Opportunities can be significant events or initiatives (merging another university's programs into yours, expanding a collaborative research or academic program), or they can be more modestly sized (sharing or outsourcing administrative functions/services with another institution).

Evaluating whether - and how - to respond to an opportunity requires the governing body and management to seek honest answers to challenging questions: What are the drivers behind this opportunity? What is the impact to the university if the opportunity is passed by? What is the impact to the university if the opportunity is acted upon? What must the university be able to do in order to maximize the value of the opportunity? Does the university have the ability to do so? Does the university have the willingness to do so? What is the impact to the university if it performs poorly when acting upon the opportunity? Who will benefit the most from the opportunity, and who will benefit the least from - or be hurt by - the opportunity? The role of the governing body is to ensure that these questions are answered honestly and that the metrics are in place to evaluate the effectiveness of the decisions made. Depending on the size of the opportunity, many governing bodies will create an ad hoc committee to evaluate it. This committee often draws representatives from both the board and senior leadership, including members of the finance and audit committees, academic committees, the development committee and the executive committee.

The role of the governing board has never been more important. And the challenge of preserving the university's brand, reputation and financial resources has never been more difficult.

\section{WHAT SHOULD YOU DO IF YOU ARE NOT A MARKET-LEADING UNIVERSITY?}

Mary F. Foster, Managing Director, Higher Education Practice, Grant Thornton LLP

On Jan. 23, 2012, Moody's ${ }^{52}$ released its outlook for higher education for the next year. The message was mixed: If you are a market-leading private or public college or university, you have a stable outlook. All other colleges and universities have a negative outlook. While that doesn't mean that your debt will be automatically downgraded, it does signal the agency's concerns about the strength of universities that are highly dependent on state appropriations and tuition. We don't purport to know how Moody's will rate your debt, but there are some strategies that can help you strengthen your institution.

In simple terms, a market-leading university is an institution that has global brand-name recognition in academic and research that support its tuition pricing. That doesn't mean that tuition pricing isn't at a tipping point - it is - but rather that these institutions can set the tuition level either higher or lower and still have enough endowment revenue to allow for discounts and scholarships. These institutions attract a highly selective student body and have sufficient endowment funding to considerably subsidize top talent. They have generous philanthropic support, diversified research funding sources, and low dependence on state funding. They possess multiple business lines with revenues from diverse sources, provide comprehensive academic offerings, and (often) have multisite operations. And finally, they have strong balance sheets and healthy liquidity, both of which offer good support for debt service and ongoing operations.

For the thousands of universities that are not market leaders as defined above, there are still strengths upon which new strategies can be established. These strategies can be developed to maximize the institution's brand, revenues and operating performance. The more nimble institutions have already adopted some of these strategies.

First, though, the following facts need to be considered:

\footnotetext{
52 Tuby, Kimberly S. “U.S. Higher Education Outlook Mixed in 2012,” Moody’s Investor Services, Jan. $20,2012$.

(C) 2012 The Clute Institute http://www.cluteinstitute.com/
} 
Personal net worth at the end of 2011, as measured by a Federal Reserve Statistical Release, remained more than 10 percent below 2007 levels. ${ }^{53}$ This means that there will be long-term pressure on tuition pricing.

Regional population changes for the next 10 years will have an impact on recruitment strategies. Projected population growth figures, coupled with immigration statistics from the past 10 years, can inform strategic decisions about which students to court. Regional population projections through 2020 reflect annual 1 percent growth in the South, with peaks at 1.5 percent in 2016, 2017 and 2018. The Northeast will experience yearly population declines, with a cumulative reduction of 1 percent by 2020 . The Midwest's population figures will likely hover between zero percent annual growth and negative 0.5 percent growth in the next 10 years. ${ }^{54}$ And the West will probably see yearly growth rates ranging between 0.5 percent and 0.75 percent through 2020.

Online education is here to stay and has been proved to be an effective teaching tool, especially when integrated with campus-based programs. The number of students who have taken at least one online course has increased, rising from 10 percent in 2003 to 30 percent in 2010. The Sloan Consortium projects that this percentage will grow to 50 percent by $2016 .^{55}$

Federal research funding will become increasingly competitive. Top-tier research institutions will retain their share of federal dollars, but that funding will drop to pre-ARRA levels and experience slow levels of growth going forward.

Covering the costs of research facilities and infrastructure will become more difficult for colleges and universities that are not top-tier institutions.

Endowment spending will continue to be impacted by the losses experienced between 2007 and 2009 . Since spending rates are based on investment balances averaged over three- to seven-year periods, the amounts available for spending will likely remain below prerecession levels. In addition, the states (almost all of them) that adopted the new Uniform Prudent Management of Institutional Funds Act rules have included reasonableness tests for establishing prudent spending rates, and some states have set a percentage ceiling above which the institution must demonstrate that the spending rate is prudent.

State appropriations would have declined more sharply over the last several years had ARRA funds not eased the short-term pain. The median for state appropriations totaled 33.4 percent of public universities' operating revenue in 2006 and 29.1 percent in 2010. According to the American Association of State Colleges and Universities, 35 states foresee cuts in 2012 state appropriations to four-year universities, and 13 of those states expect the cuts to be in the double digits. ${ }^{56}$

Proposed cuts to federal Medicaid funding include capping the payments for graduate medical education at the national average salary for (physician) residents. These cuts would hurt teaching hospitals in high-cost urban areas where a resident's salary is higher than the national average.

Focusing on top-line revenue strategies will present challenges unless the institution is willing to consider new approaches to diversifying sources of revenue, including tuition revenue. This can mean considering new student cohorts, new student markets and new partnerships with businesses. The goal is to play to your strengths as an institution. Each college and university is unique and attracts a certain type of student; look for synergies between your existing cohorts and new cohorts such as adult and online learners, commuters, veterans and municipal employees.

\footnotetext{
53 Ibid.

${ }^{54}$ Van Der Werf, Martin, and Sabatier, Grant. The College of 2020: Students, June 2009 (report cites Beth McMurtrie in "Global Downturn Is Not All Bad News for International Educators," The Chronicle of Higher Education, March 6, 2009); Moody's Investors Service, Special Comment, “U.S. Expansion Offers Opportunities and Risks for Universities,” Nov. $28,2011$.

${ }_{56}^{55}$ Tuby, Kimberly S. “U.S. Higher Education Outlook Mixed in 2012,” Moody’s Investor Services, Jan. $20,2012$.

56 Ibid. 
Know your region's economic development plan so that your career placement activities strengthen your brand. Look to those economic plans to understand the needs of new businesses being recruited to your area, and reach out to new student markets with tailored course offerings. Look to partner with two-year institutions in order to gain a preselected pipeline of students.

As the population trends indicate, you may be losing students in your region. Know where your alumni live, work and retire, and use your alumni network to cost-effectively tap into new recruiting markets and strengthen your brand. Forging into new U.S. or global markets can be expensive and ineffective if brand awareness isn't already there.

In some regions, there will be opportunities for medium-sized and large institutions to expand their campuses by assimilating smaller schools. Constructing new buildings can entail a hefty amount of start-up funding. On the other hand, the economies of scale involved in attracting a larger student body while avoiding construction costs and eliminating redundant administrative expenses can benefit top-line revenues and bottom-line margins. Assimilating a smaller school can also help the university tap into new markets and reinforce its brand.

There may also be opportunities for an institution to share its campus with businesses, union training programs, Department of Labor job development and skills programs, and Board of Cooperative Educational Services centers. Campus facilities can be used year-round - even on the weekends and in the evenings and early mornings.

And lastly, think again about shared services opportunities with other institutions — including colleges. Play to your strengths, and charge these institutions a fee for the strong administrative and academic services that you already perform. Career counseling, budget monitoring, data management, construction management, transportation services, and day care and training programs are a few such services. The list can go on. The goal is to look at all university cost centers and departments, and brainstorm about how to generate revenues from the same functions that are considered costs covered by tuition.

All of these actions require the institution to be engaged with its local community and cognizant of its needs, opportunities and challenges. Meeting someone's challenges can become a new revenue stream for your institution. This type of engagement also heightens visibility for the university, garners brand recognition, allows for the type of partnering that facilitates fundraising (friend-raising equals fundraising potential), and creates multiple sources of revenue. It can help with research funding, depending on how strong your existing research base is. It can also help you create a unique market niche that serves as a platform to attract top talent — whether faculty or students - to the university.

Of course, this won't happen in one year. But now is the time to begin anew and play to your strengths. 


\section{ABOUT GRANT THORNTON'S SERVICES TO NOT-FOR-PROFIT ORGANIZATIONS}

Grant Thornton has extensive experience providing audit, tax and advisory services to some of the most sizable and complex not-for-profit institutions in the country. Our not-for-profit practice is currently the second largest among national accounting firms, with more than 3,000 clients across the United States. We are the only large international accounting firm to have a team of fully dedicated professionals from staff to partner who work exclusively with not-for-profit clients.

From top management down, Grant Thornton is strategically committed to the not-for-profit industry. We provide complimentary educational forums on timely topics through our Board Governance Institute. We also demonstrate our thought leadership through numerous newsletters, articles and speaking engagements nationwide on important not-for-profit business and governance topics.

Grant Thornton's not-for-profit practice has a well-earned reputation for providing clients with the highest quality service with innovative solutions, personal attention and measurable results.

\section{TAX PROFESSIONAL STANDARDS STATEMENT}

This document supports Grant Thornton LLP's marketing of professional services and is not written tax advice directed at the particular facts and circumstances of any person. If you are interested in the subject of this document we encourage you to contact us or an independent tax advisor to discuss the potential application to your particular situation. Nothing herein shall be construed as imposing a limitation on any person from disclosing the tax treatment or tax structure of any matter addressed herein. To the extent this document may be considered to contain written tax advice, any written advice contained in, forwarded with, or attached to this document is not intended by Grant Thornton to be used, and cannot be used, by any person for the purpose of avoiding penalties that may be imposed under the Internal Revenue Code.

\section{CONTACT}

For additional information on topics covered in this document, contact your Grant Thornton LLP adviser or Frank Kurre.

Frank Kurre

National Managing Partner

Not-for-Profit and Higher Education Practices

T 212-542-9530

E frank.kurre@us.gt.com

Content in this publication is not intended to answer specific questions or suggest suitability of action in a particular case. For additional information on the issues discussed, consult a Grant Thornton client service partner.

(C) Grant Thornton LLP

All rights reserved

U.S. member firm of Grant Thornton International Ltd

Re-printed with permission from the Grant Thornton website:

http://epic2020.files.wordpress.com/2012/05/state_of_higher_education_2012_whitepaper_print.pdf 